\title{
A SEXUALIDADE NO HORIZONTE DO DISCURSO PÓS-MODERNO
}

\author{
Clenio Lago ${ }^{1}$ \\ Sabryna Joane Voos Bortoncello Tarouco 2 \\ Edinaldo Enoque da Silva Junior ${ }^{3}$
}

\section{Resumo}

No momento de crise dos referenciais em que as relações passam do âmbito da estabilidade (até que a morte os separe, para eternas enquanto durem), a serem fruídas, voláteis, sem muita estabilidade, que qualquer comportamento parece correto, importa compreender o processo constitutivo da sexualidade, no horizonte do discurso pós-moderno. Para tanto, utilizou-se de pesquisa bibliográfica e coleta dos dados por meio de entrevistas individuais estruturadas com base em socialização e debate do tema no momento da entrevista. Com a pesquisa pode-se concluir que a crise moderna dá origem a várias "desconstruções" e traz como continuidade desse processo a pós-modernidade, com suas crises e quebra de tabus, mostrando-nos o quanto as relações pós-modernas estão vazias, inseguras e fragmentadas, mas representa um momento, um enfoque histórico que não pode ser ignorado, à medida que coloca em cena o humano em seu devir contingencial. Contudo, constitui possibilidade de diálogo enquanto poder fazer emergir a diversidade, que se, apenas em si, por si e para si é temerária e egoística.

Palavras-chave: Formação; Sexualidade; Discurso; Pós-Moderno

1 Filósofo, Mestre e Doutor em Educação. Endereço: Rua Oiapoc, 211 Bairro Agostini, 89900000 - São Miguel do Oeste, SC - Brasil. Endereço eletrônico: cleniolago@ yahoo.com.br ${ }^{2}$ Acadêmica do curso de Psicologia da Unoesc/São Miguel do Oeste. Bolsista de iniciação científica. Endereço: Rua Oiapoc, 211, Bairro Agostini, 89900000 - São Miguel do Oeste, SC - Brasil. Endereço eletrônico: sabrybortoncello@gmail.com

${ }^{3}$ Doutorando em Educação pela Unijui, Mestre em Educação pela Universidade do Oeste de Santa Catarina (UNOESC). Graduado em História, especialista em Ciências Sociais. Endereço: Rua Oiapoc, 211 Agostini, 89900000 - São Miguel do Oeste, SC - Brasil. Endereço eletrônico: enoquesmo@ hotmail.com 


\section{INTRODUÇÃO}

Em todos os momentos da história o corpo feminino e masculino, assim como a sexualidade, é evidenciado pelos parâmetros e valores que embasam a época vivenciada em meio aos seus desafios, constituindo-se em referenciais identitários. O horizonte do debate é de que toda e qualquer organização social que se estruture, para se manter precisa lidar, dar vazão, coordenação à dimensão sexual do humano, à sexualidade, este princípio eruptivo do humanar. Isso seja enquanto controle, liberação, capacidade criativa, inventiva do humano em si mesmo (princípio de individuação) e enquanto humano geral (princípio de desconstrução), para fazer emergir outro, seja canalizado, calanizável. De outra maneira, “[...] a sexualidade revela-se um domínio importante para a constituição do sujeito [...]” (CANDIOTTO, 2015, p. 347), no sentido de que permite pensar e ressignificar as técnicas de si, como uma espécie de escritura, reescritura de si para além da normalização disciplinar, como possibilidade de uma estética de si. Por outro lado, hoje, a sexualidade perde da dimensão do si na relação para emergir como condição de desejo, como sopesa o argumento de Candiotto (2015, p. 351), para quem "entre nós predomina, ainda, uma descontinuidade de natureza entre o sexual e o social como postulado para decodificar os conteúdos sociais em termos sexuais." Nesses termos, a expressão sexualidade, que significa relação, linguagem, expressão, condição humana foi transformada em sexo como desejo ${ }^{4}$ puro, desvinculado de projeções sociais. "Porque a sexualidade tem sido pensada a partir do desejo (enquanto pecado no cristianismo), foi necessário postular um bloqueio entre o sonho e seu conteúdo pelos mecanismos de repressão e conversão, de modo a permitir que o conteúdo do sonho seja compreendido como a repressão da verdade do desejo." (CANDIOTTO, 2015, p. 351). Isso significa que a sexualidade, a forma como lidamos com ela, os discursos, num contexto de que somos linguagem, ocupa um lugar central da constituição do sujeito, seja via valorações de comportamentos, juízos de valores, seja como manifestos ou mesmo cuidado de si. Nesse sentido, no discurso moderno e pós-moderno,

\footnotetext{
4 "Se entre os gregos, o desejo era uma força intempestiva ao lado da natureza; se entre os greco-romanos ele se torna um objeto a ser analisado e conhecido; no cristianismo, ele passa a ser algo constitutivo do sujeito. A relação entre subjetividade e verdade não está focada na confissão objetiva do pecado, mas na sua raiz ontológica e na sua verdade mais radical que é a concupiscência ou o desejo de pecar. Desde então, a questão central não será como fazer uso dos prazeres, mas identificar qual a verdade do desejo que habita no sujeito e que deverá ser interminavelmente autoanunciada. [...] pode-se concluir que a cultura greco-romana deu nascimento à objetivação do desejo, mas foi somente no cristianismo que o homem ocidental tornou-se homem de desejo, antes mesmo de ter se transformado em um animal confidente no dispositivo moderno da sexualidade." (CANDIOTTO, 364, p. 2015).
} 


\begin{abstract}
A sexualidade ocupa um espaço central na formação do sujeito, porque ela remete para uma experiência individual, para o envolvimento da personalidade à volta dessa experiência, que é ao mesmo tempo um vivido pessoal, uma relação com o outro e, mais profundamente, uma consciência de si voltada para a relação com a vida e com a morte. O que aqui é dito tem uma consequência imediata. A sexualidade é a construção de comportamentos de sexo. Há, pois que reconhecer a existência de condutas sexuais que não contribuem para a construção de uma sexualidade complexa, mas comprovam a autonomia do sexo, único que possibilita a construção da sexualidade. Esse sexual isolado da sexualidade como construção cultural é aquilo a que nós chamamos o erotismo. A sua ambiguidade e a sua importância resultam do fato de em primeiro lugar ele continuar a ser sexo, mas esconder também uma relação consigo e com os outros. Se ele for inteiramente destacado de tudo o que é a sexualidade, degradar-se-á em pornografia. Penso que a relação sexualidade moderna e pós-moderna se dá na sexualidade/erotismo. (TOURAINE, 2005, p. 19).
\end{abstract}

As descobertas científicas permitiram a homens e mulheres livrarem-se da preocupação de terem filhos acidentais e a conseguirem ter os filhos desejados. As relações parecem deixar de ser primeiramente de cunho afetivo para basearem-se na dimensão estética, no prazer. A estetização dos corpos, dos espaços, são expressões desse processo, uma vez que homens e mulheres gastam fortunas à procura do corpo perfeito (se é que tal coisa pode existir) para encantar e seduzir a quem possa interessar, mas, acima de tudo, a si mesmos, como é o caso de jovens que realizam cirurgias plásticas. Efetivam-se mudanças de sexo, o consumo de estimulantes do apetite sexual, como forma de sensação de vidas intensamente vividas. Nesse sentimento, a perspectiva de transgressão pelo sexo pode se dar a transgressão da sexualidade, da identidade, alienadas culturalmente em outras sexualidades. Assim, a sensação de vida parece ser sentida no lançar-se desreferenciado, o que, no fundo, provoca um intenso revisar da condição humana.

Desse modo, em meio às transformações sociais, somos lançados nos turbilhões das membranas televisivas, internéticas. Querendo ou não somos influenciados pelas mensagens erotizantes subliminares, que inconscientemente moldam os gostos e preferências, das mais simples às mais complexas, a partir de comportamentos essencialmente questionadores, apelativos, que a cada instante lançam moda, dizem que o que está instituído não é, para logo em seguida apresentar o suposto ser, esvaindo, sugando energeticamente o ser. É como se fossemos incessantemente bulinados, masturbados, mas com a sensação final de gozo deficitário, precário, insatisfatório, motor do consumismo. A erotização do corpo salta assustadoramente da intimidade para a exposição banal, dando origem a uma nova discursividade do sexo e do eu. As relações parecem cada vez caminhar por esse caminho. É o que nos alerta Touraine (2001, p. 98): 
O seu corpo não é uma adição de pernas, de um rosto, de um peito, é um conjunto. Ora, a noção de corpo está ameaçada pela mercantilização da sexualidade. Olhe os anúncios: a atenção é fixada numa mão, nuns seios, numa cabeça, de maneira fetichista.

Assim, vivenciamos comportamentos antes tidos como anormais e recriminados. Os princípios delineadores do certo e do errado parecem estar dissolvidos, não mais existindo. Parece estarmos vivendo a "entre-ser", mais radicalmente no não ser.

Portanto, o que se tem é que uma sociedade, identidade, estrutura-se, mantém-se enquanto organização tendo a sexualidade como uma dimensão essencial do humano, essencial no sentido de controle e de abertura: como elemento importante do humanar, à medida que se constitui uma centralidade dinâmica constitutiva, autoconstitutiva do si. É nesse sentido que perguntamos em que pesa o discurso pós-moderno?

A pós-modernidade com suas transformações já faz parte do caminhar humano e seu estudo permite o amadurecimento social e o enriquecimento cultural àquele que procura compreender o novo espírito do tempo e seus impactos na formação do ser humano. Algumas perguntas surgem com essas transformações: como é construída a sexualidade do homem e mulher atual? Quais são os constructos simbólicos circundantes nos relacionamentos pósmodernos?

\section{DO DISCURSO MODERNO AO DISCURSO PÓS-MODERNO}

A modernidade surge marcada pela ruptura com o passado, postulando emancipação e autonomia do homem como sujeito histórico. Mas, sua história é marcada por uma grande decepção com acentuada infelicidade, incerteza do futuro, de acidentes nucleares, guerras atômicas, efeito estufa, fanatismos, assaltos, sequestros, doenças, totalitarismos, por um profundo descrédito do homem para o homem. Assim, no início a modernidade era vista como "um projeto do mundo que viria, controlado pelos humanos." (BAUMAN, 2008, p. 87), com créditos emancipacionistas. Hoje, é compreendida ao período histórico iniciado no século XV, onde houve uma mudança no pensamento da realidade e no modo das relações entre o ser humano atual e das gerações anteriores (DUARTE JÚNIOR, 2002, p. 13), referindo-se então ao estilo, costume de vida ou organização social, iniciada na Europa e mais tarde tornando-se mundial (GIDDENS, 1991). 
Para Stein (1991), a modernidade é um período onde se tem uma espécie de padrão da razão, de sistema filosófico, onde o indivíduo deve-se comportar de tal forma em virtude de haver um padrão de valores que devem ser seguidos para que seja aceito pela sociedade. Rejeitou o modelo antigo radical, que impunha uma sociedade cética/cínica/estoica, do compromisso baseado na sabedoria, rejeitando também a visão cristã baseada na confiança e temor a Deus (BAUMAN, 2008, p. 86), que antes colocava as crenças práticas e religiosas como um refúgio das tribulações da vida cotidiana. "A modernidade não é perturbadora apenas devido à circularidade da razão, mas porque a natureza desta circularidade é decisivamente intricante" (GIDDENS, 1991, p. 55), visto a razão ter sido eleita como a dimensão humana, crivo sob o qual tudo deveria ser julgado.

Quando Habermas (2002, p. 10) analisa a modernidade afirma que "a época 'moderna' confere ao conjunto do passado a qualidade de uma história universal [...]”, cuja história é marcada pela racionalidade. Por racional, Habermas (2002, p. 5) entende como sendo o "[...] processo de desencadeamento ocorrido na Europa que, ao destruir as imagens religiosas do mundo, criou uma cultura profana [...]”, iniciando assim o desenvolvimento das sociedades modernas. E explica que o conceito de modernização seria referente "[...] à formação de capital e mobilização de recursos, desenvolvimento das forças produtivas e ao aumento da produtividade do trabalho [...]", secularização de valores e normas. Assim, a modernidade resultou em "um modo de vida totalmente diferente dos anteriores até então vividos, sem precedentes não teve um modelo a ser seguido", ocasionando profundas mudanças em relação à maioria dos períodos anteriores, principalmente na forma como o homem se percebia dentro da sociedade (GIDDENS, 1991, p. 15). Sua aposta racionalista rompeu o mundo sagrado, um mundo criado pela vontade divina, até então vivenciado, substituindo Deus pelo homem a guiar-se pela racionalidade científica (TOURAINE, 2002). Dissolvem-se as formas de vida tradicionais, formando-se identidades abstratas do eu.

Giddens (1991, p. 15) enfatiza “as 'descontinuidades' produzidas pela modernidade que se tornaram cada vez mais visíveis em virtude do ritmo em que tais mudanças ocorreram." Cita também como característica o escopo da mudança, onde a transformação social transformou as identidades, penetrando virtualmente toda a superfície. E, por fim, (GIDDENS, 1991) caracteriza a natureza intrínseca das instituições modernas também como transformada. A consequência da modernidade é a globalização, em que cria novas formas de riscos e perigos, ao mesmo tempo promove possibilidades ao longo alcance. "Soltam-se as amarras da tradição do que foi por muito tempo 'posição de vantagem' - o domínio das 
situações e valores" (GIDDENS, 1991, p. 174), o que faz emergir o ser humano em sua perspectiva pós-moderna.

O homem moderno é fruto da falta de autoconfiança da vontade humana, por isso deve ser guiado pelo entendimento, pois a presença da ambivalência não nos permite mais esperar o futuro, deixando-nos cada vez mais inseguros do que vai acontecer daqui para frente, dividindo nossa liberdade entre o que eu posso fazer com o que eu quero que seja feito, e, ao mesmo tempo, tendo a certeza de que não existe verdade absoluta - ceticismo (BAUMAN, 2008). Agora, nada pode ser conhecido com alguma certeza, desde que se apresentem fundamentos (GIDDENS, 1991), pois tudo é posto em dúvida. Mas ao mesmo passo que a modernidade teve como consequência para o homem as incertezas e o abandono, tornou-o livre de certa forma para poder "desfrutar" das possibilidades que o mundo moderno juntamente com as inovações tecnológicas e sociais proporcionou, dando direito à liberdade de opinião e tentando estar dentro de certos limites racionais. "Somos - a maioria de nós livres para aproveitar nossa liberdade, mas não para evitar as conseqüências desse desfrute" (BAUMAN, 2008, p. 94). Conforme Touraine (2002), a liberdade ou liberação de certos controles das formas até então tradicionais de autoridade, permite a felicidade, mas não a garante, tal ideologia garante mais ainda a sociedade da produção, consumo, imediatismo (TOURANE, 2002, p. 10).

Para Hall (2000), um tipo de mudança estrutural está ocorrendo nas sociedades modernas desde o final do século XX, fragmentando as paisagens culturais de classe, gênero, sexualidade, etnia, raça e nacionalidade, que no passado nos forneciam sólidas localizações como indivíduos sociais. Tais transformações estão também mudando nossas identidades pessoais, abalando ideias que temos de nós mesmos como sujeitos integrados. Essa "perda de um sentido de si", um duplo "deslocamento" ou "descentração" do sujeito tanto do mundo cultural, social, quanto de si, evidencia ainda mais uma crise de valores (HALL, 2000, p. 10). "O que, de fato, está em crise é o projeto modelo de conhecimento e seu sentido humano." (GOERGEN, 2012, p. 161).

Percebendo que toda essa mudança de padrões até então nunca, dessa forma, vivenciada, a sociedade toma um rumo totalmente diferente. Nas palavras de Nietzsche (2005a), com a morte de Deus, do qual somos todos culpados, o homem desprende-se do seu sol e deixa de existir um em cima, em baixo, atrás, na frente..., referenciais de certeza. Não caímos como que num nada, constantemente? Com base nessa constatação, encerra-se o período moderno, não dando conta de explicar o papel da sociedade, dos indivíduos em uma 
única perspectiva e a pós-modernidade, muitos discursos começam a ter espaço, movidos por mais transformações de pensamento, cultura e atitudes frente à vida.

A pós-modernidade seria "a modernidade que atinge maioridade olhando-se a distância, e não de dentro, fazendo um inventário completo de ganhos e perdas, psicanalisando-se, descobrindo as intenções que jamais explicara, descobrindo que elas são mutuamente incongruentes e se cancelam." (FENSTERSEIFER; WERLANG, 2006, p. 37).

Não há mais verdades, referenciais absolutos naturais ou imutáveis, pois as formas são uma invenção de nosso espírito que não se pode pensar a não ser vendo todas as coisas da sua janela completamente falsificadora, completamente falsificada, do seu modo, da sua forma (TOURAINE, 2002). A pós-modernidade desperta, como já mencionado, um sentimento de incerteza, com isso a falta de clareza do mundo (razão) retrocede juntamente com a vontade (desejo). "O mundo é sólido como uma rocha e não inspira dúvidas quando se trata de ações habituais, rotineiras" e quando essas ações falham, ficamos sem ter para onde correr, pois quando há muita liberdade de escolha, menos óbvios e forçados parecem os sinais vindos do mundo real aqui e agora (desejo da satisfação) (BAUMAN, 2008).

A falta de clareza do mundo, por não ter mais um padrão de referência constituído, torna-se produto da ânsia por tornar as coisas "claras". A maior parte dessa ambivalência sentida se origina nos esforços difusos e disparatados para eliminar a equivocabilidade de localidades selecionadas, separadas e sempre confinadas (BAUMAN, 2008). Consideremos então que as sociedades modernas são sociedade de mudança constante, rápida e permanente. À medida que as culturas nacionais se tornam mais expostas às influências externas, é mais difícil conservar as identidades culturais ou impedir que elas se enfraqueçam por meio do bombardeamento e da infiltração cultural (HALL, 2000, p. 74).

Quanto mais a vida social se torna mediada pelo mercado global de estilos, lugares ou imagens, pelas viagens internacionais, pelas imagens da mídia e pelos sistemas de comunicação globalmente interligados, mais as identidades se tornam desvinculadas desalojadas - de tempos, lugares, histórias e tradições específicas e parecem "flutuar livremente" (HALL, 2000, p. 75). A pós-modernidade transforma a sexualidade em produto a ser comprado e utilizado com as imagens dos atuais meios de comunicação, ora servindo de distração, ora de produtos mercadológicos, mas informando um modo, ou modos de ser.

Conforme Touraine: 
forma de uma comercialização do erotismo, ou mesmo da pornografia, enquanto nas sociedades individualistas, a sexualidade é uma das expressões centrais de uma identidade que deixou de ser enquadrada por balizas sociais e culturais gerais. (TOURAINE, 1997, p. 56).

Por isso, o "sujeito pós-moderno" parece perdido em meio às mensagens dos meios que os circundam. E um "inocente" programa de entretenimento dominical repleto de mensagens erotizantes absorve o sujeito para o consumismo sexual sem que este conscientemente tenha se dado conta. "O produto está pronto para o uso imediato, o prazer passageiro, a satisfação instantânea.” (BAUMAN, 2004, p. 21). Não se tem mais esforços prolongados para desfrutar de alguma coisa, garantias de prazer total e, no caso de insatisfação, devolução do dinheiro (BAUMAN, 2004, p. 21). Assim, diante de tantas facilidades consumidoras de economia de tempo, o amor se torna algo frágil, sem esforço para conquistá-lo e muito menos para mantê-lo. Quando se obtém êxito nessa tarefa torna-se a enfraquecer até o momento de sua inexistência, "é uma hipoteca baseada num futuro incerto e inescrutável.” (BAUMAN, 2004, p. 23).

Dessa forma, o desejo difere do amor, sendo um impulso de autodestruição, contaminado desde seu nascimento pela vontade de morrer (obtenção do prazer total). "Se o objeto quer consumir, o amor quer possuir [...]. Se o desejo se autodestrói, o amor se autoperpetua." (BAUMAN, 2004, p. 24). É o que retrata Bauman (2011, p. 88), quando fala que o "[...] o desejo tem a si mesmo como objeto constante, e por essa razão está fadado a permanecer insaciável [...]" Já o amor desperta a vontade de cuidar, de preservar o objeto cuidado, um estímulo a proteger, alimentar, abrigar, acariciar, afagar e mimar, ao lado do ciúme, que desperta a vontade de guardar, cercar, "amar significa estar a serviço, colocar-se à disposição, aguardar a ordem. Mas também pode significar expropriar e assumir a responsabilidade.” (BAUMAN, 2004, p. 24).

Segundo Adrienne Burges (apud BAUMAN, 2004, p. 25), o compromisso é uma consequência aleatória de outras coisas: nosso grau de satisfação com o relacionamento; se vemos uma alternativa viável para ele; e se levá-lo adiante nos causaria uma perda importante em matéria de investimentos (tempo, dinheiro, propriedades em comum, filhos), para assim avaliar se vale a pena tal investimento. A satisfação na relação depende muito do retorno do investimento que um parceiro espera do outro, o que evidencia que, em primeiro lugar, procuramos segurança: "a proximidade da mão amiga quando você mais precisa dela, o socorro na aflição, a companhia na solidão, o apoio para sair de uma dificuldade, o consolo na derrota e o aplauso na vitória.” (BAUMAN, 2004, p. 24). Assim como nas horas de 
gratificação espera-se um reconhecimento do parceiro, coloca-se também que as promessas de compromisso não duram muito tempo. Desse modo, quando no relacionamento não se constrói a esperada confiança, a estabilidade da relação é ameaçada, o frágil relacionamento torna-se uma relação submissa e com poder absoluto de determinado parceiro, destruindo a autonomia e sufocando o outro. Nessa relação também se desenvolvem problemas na comunicação, desejando ainda mais mudar o outro. "Já que o amor não deixa de ser possessivo, há sem dúvidas esperança de mudança, a vida organizada em torno do consumo [...] é orientada pela sedução, por desejos sempre crescentes e quereres voláteis, o céu é o único limite." (BAUMAN, 2011, p. 90). Como consequência desenvolvem-se "relações de bolso" doces e bem-sucedidas, porém de curta duração. Não havendo o que fazer para aproveitá-la, “é a encarnação da instantaneidade e da disponibilidade.” Não há apaixonamento, pois quanto menos investimento menor é a insegurança em relação ao outro. "Assim que você perceber que as coisas estão saindo do controle vá adiante, deixe o bolso livre" (BAUMAN, 2004, p. 94): amor líquido, liquidado.

Dessa forma, Bauman (2004) coloca que amamos a nós mesmos como ser único, amamos nossa singularidade e a do outro como subjetivas e não intersubjetivas. Ou seja, o jogo não poder fugir ao controle, é um jogo estritamente subjetivista, racionalizado e, ao mesmo tempo, permissivo. Assim, a relação se torna um compromisso se cada um pode ganhar de alguma forma e onde só continua se ambas as parte permanecem satisfeitas. $\mathrm{O}$ compromisso alimenta a esperança de "até que a morte nos separe", mas, ao mesmo tempo, querendo evitá-lo a todo e qualquer custo. Desse modo, se você sabe que seu parceiro pode "abandonar o barco" a qualquer momento, com ou sem seu consentimento, investir de forma absoluta se torna totalmente inviável, uma vez que é sempre arriscado aceitar a fidelidade do outro, pois isso o torna dependente de certa forma de seu parceiro. Nesse contexto, desenvolvem-se parcerias frouxas, fracas e sem valor. $\mathrm{O}$ tempo que antes era investido para conquistá-lo agora se torna insignificante frente à relação. Ao mesmo tempo que se desenvolveram tantas facilidades de prazer imediato, há também o ressentimento do abandono. A busca pela escolha certa, a esperança, a não certeza, os vínculos sem experiência comum, relacionados somente com o prazer imediato e absoluto. Desaprende-se a arte de negociar na relação, pois não se desenvolve mais a habilidade para conviver com as diferenças.

O sujeito pós-moderno nesse contexto, se é que podemos falar de sujeito, não possui mais uma identidade fixa, essencial ou permanente. A identidade a partir daí torna-se uma 
“celebração móvel” formada e transformada continuamente em relação a formas pelas quais somos representados ou "interpelados" nos sistemas culturais que nos rodeiam. Assim, Hall (2000) considera que dentro de nós há identidades contraditórias, com identificações deslocadas. A identidade até então permanente, unificada, completa, segura e coerente, nos dias de hoje torna-se uma fantasia, pois, a partir do momento em que os sistemas de significação e representação cultural se multiplicam e se pluralizam, somos confrontados por uma multiplicidade desconcertante e cambiante de identidades possíveis, que poderíamos nos identificar temporariamente. Nisso parece ganhar sentido as leituras de Nietzsche, quando afirma que "Não existe Coisa-em-si, nenhum conhecimento absoluto; o caráter perspectivista, ilusório, enganador é intrínseco à existência” (NIETZSCHE, 1989, p. 77); que o “"Eu' trata-se de uma hipótese auxiliar com vista à inteligência do mundo.” (NIETZSCHE, 1989, p. 73). Mas o problema é que nem à radicalidade destas frases se chegou, pois o homem nem se percebe como algo maior do que as metanarrativas anteriores e a ausência de narrativas, visto estar enredado em um novo discurso, o discurso pós-moderno.

Nas palavras de Lyotard (2006, p. xvi), “[...] considera-se pós-moderna a incredulidade em relação aos metarrelatos", aos metadiscursos, o que já estava explícito em Nietzsche. O grande relato perdeu sua legitimidade, não importando qual seja o modo de unificação. Isso significa novos, outros vínculos sociais, para além do bem e do mal, existentes.

\section{DESCRIÇÃO METODOLÓGICA}

A pesquisa de campo foi realizada em um município do oeste catarinense, com sujeitos de várias faixas etárias. Adolescentes, com idade de 12 a 18 anos, adultos com idade de 19 a 50 anos, e idosos com idade acima de 51 anos. A preocupação esteve focada nas compreensões de sexualidade dos sujeitos. Embora sendo um município distante dos grandes centros, percebe-se uma mudança radical na forma de perceber a sexualidade para com a tradição vigente até então, vivendo-se de forma mais impactante a crise de valores, visto as culturas locais terem permanecido quase intactas por um bom tempo.

A pesquisa abordou assuntos, como: modernidade, pós-modernidade e a sexualidade na perspectiva dos dois discursos. Foram realizadas 52 entrevistas estruturadas com aproximadamente 30 minutos de duração, com adolescentes/jovens, adultos/adultas e 
idosos/idosas. Dentre os grupos houve resistência por parte de alguns idosos e com isto não foi possível realizar as 10 entrevistas previstas com esta classe de entrevistados, sendo realizadas apenas duas, totalizando 52 entrevistas. Os entrevistados pertenciam a diferentes contextos sociais, sendo possível obter um resultado mais amplo em virtude das realidades apresentadas.

O questionário foi construído a partir das questões levantadas no problema da pesquisa e na bibliografia pesquisada, como: o que é sexualidade; a percepção de ato sexual e de sexualidade; a percepção da mudança em relação aos valores morais da sociedade; a percepção da forma como hoje a sexualidade é abordada entre as relações humanas; a percepção de hoje sobre o casamento; a percepção sobre o papel da mídia na construção e nas vivências da sexualidade; a percepção do ato sexual e das relações afetivas.

Em algumas questões houve espaço para que os comentários pudessem ser explicitados e assim fosse possível analisá-los de forma qualitativa. Percebe-se que a maioria dos comentários partiu do público adolescente, de ambos os gêneros, possibilitando uma reflexão quanto à naturalidade da faixa etária em expor a sua opinião sobre o tema.

As entrevistas foram realizadas em diferentes locais, em alguns casos fez-se necessário ir à casa dos participantes e, em outros, foram realizadas em locais públicos. Iniciou-se socializando a história da sexualidade por meio de conversa, em seguida houve a aplicação do questionário. Em alguns casos houve debate a respeito do tema abordado, já que para muitos ainda é considerado um tabu. A pesquisa empírica visou à obtenção de informações que permitissem compreender como as transformações da sociedade precisavam ser interpretadas e compreendidas pelas ciências que se propõem sociais e configuradas em saber. Após este momento, organizou-se os dados e analisou-os considerando a bibliografia.

\section{RESULTADO E ANÁLISE}

A pós-modernidade com suas transformações já faz parte do caminhar humano e seu estudo permite o amadurecimento social e o enriquecimento cultural àquele que procura compreender o novo espírito do tempo e seus impactos na formação do ser humano.

Na disposição e análise dos resultados, optou-se por considerar três grandes fases do desenvolvimento, visto os impactos da crise da modernidade estarem sendo sentidos nas últimas décadas. De alguma forma, idosos veem seus valores entrarem em crise, os adultos, 
podemos dizer, constituem o período da crise e os adolescentes/jovens são filhos da crise, como fica evidente pelos resultados da pesquisa, fazendo-se sensível à sensação de crise, especialmente para os idosos e adultos. Assim, para cada fase do desenvolvimento há uma percepção no que se refere à sexualidade.

Podemos observar que para alguns adolescentes a sexualidade vai além do ato sexual, percebe-se isto nas falas como: É uma forma de demonstrar amor e carinho pelo parceiro (Adolescente Fem 1); Penso que a sexualidade não se restringe apenas ao ato sexual, mas sim à maneira como nos relacionamos aos nossos parceiros e o modo como encaramos o assunto em diversos momentos (Adolescente Fem 4); É algo que só se faz com quem se tem amor. E assim como se preserva a natureza se preserva nosso corpo (Adolescente Fem 5). Já, para os adultos, o que mais marca é o fato de no passado ser tudo reprimido, escondido e proibido. É o que comprova Foucault (1988, p. 38) ao dizer que

Com a chegada do século XVII a repressão toma ainda mais lugar nas sociedades burguesas. A preocupação girava em torno de "'assegurar' o povoamento, reproduzir a força do trabalho, reproduzir a forma das relações sociais" proporcionando assim uma sexualidade economicamente útil para a sociedade e ao mesmo tempo conservadora.

Percebemos isto em algumas falas dos adultos, para quem: $O$ assunto sexualidade está sendo mais comentado, antes muitos acreditavam que fosse realmente só o ato sexual, hoje, depois de muito se falar, sabe-se que a sexualidade é muito mais que sexo (Adulta 3); É um entrelaçado de ambos. É em minha opinião o ato sexual, ou melhor, a relação sexual sentida (entendida pela pessoa) (Adulto 1). Nos discursos das pessoas idosas, nota-se que há uma referenciação ao casamento, sendo que na época a expressão da sexualidade só era permitida entre quatro paredes e "mesmo após o casamento o sexo dos cônjuges era sobrecarregado de regras e recomendações.” (FOUCALT, 1988, p. 38). A sexualidade é um complemento de um casal se amar e formar família (Idosa 1).

Em alguns discursos em relação à percepção das mudanças no âmbito da sexualidade, verifica-se que os adolescentes relacionam algumas mudanças quanto à fidelidade, homossexualidade, responsabilidades, atitudes, valores. Verifica-se isto nas falas destacadas: tanto em questão de fidelidade quanto na evolução da sociedade em relação às pessoas homossexuais (Adolescente Fem. 1); amadurecimento das ideias, mudanças nos conceitos sobre sexualidade, responsabilidade nas atitudes (Adolescente Fem. 4). Hoje em dia existem pessoas que esqueceram os valores morais, deixando de lado o respeito, tanto com os pais 
quanto com o ato sexual. Porém ainda que pouco, algumas pessoas preservam os valores morais (Adolescente Masc. 6); Há menos valores, pouco respeito e mais liberdade (Adolescente Masc. 1).

Segundo Arán (2003, p. 405), a ruptura entre sexualidade e reprodução marca um período de turbulências na história, mudam-se os valores, as crenças e representações sobre a filiação, dando uma reviravolta na representação da relação entre natureza e cultura (ARÄN, 2003, p. 405). Para os adultos, a percepção é de que tudo está mais explícito, mais liberal, está presente na mídia. Tudo está mais explícito (Adulta 5); No passado era tudo reprimido, hoje em dia já se debate o assunto em rede nacional (Adulta 7); Hoje é mais liberal, antes se era mais proibido falar sobre o assunto, e não se tinha tanta informação. Nos dias de hoje somos mais mente aberta (Adulta 8); Hoje em dia o sexo é incentivado nas TVs sem filmes sem nenhuma barreira que impeça a exposição do sexo, e assim incentivando a fazer o sexo precocemente (Adulto 2). A sexualidade parece ter virado, muitas vezes, o eixo central das terapias, especialmente para os adultos que se percebem em meio ao fogo cruzado, na encruzilhada do tempo.

Hoje tudo está mais explícito e acessível dentro das relações afetivas, a sexualidade é vivenciada de forma, julgada como natural e prazerosa por alguns, e, ao mesmo tempo, é motivo de vergonha e receio ao ser abordada, por outros. Falar em sexualidade nos dias atuais é estar ciente de que muitas mudanças já ocorreram, considerando o acesso ao prazer e não mais somente à reprodução. Estes apontamentos são perceptíveis nas falas anteriores.

Contudo, o que está posto, parece ser uma confusão, pois a sexualidade é compreendida, na maioria das vezes, como sexo, desejo. Ao menos desde a lógica dos discursos pós-modernos mercantilizados que exploram a sensação de liberdade enquanto liberdade de gozo, num mundo em que tudo é privado. Isso porque, as relações concretas vêm se efetivando no âmbito da liquidez, da constante estimulação e pouca demora. Nas palavras de Welsch (1995, p. 18, grifo do autor): "uma esteticização total leva em direção ao seu oposto. Onde tudo é belo, nada mais é belo; estimulação ininterrupta conduz ao embotamento; esteticização vira anestetização." A sensibilidade fica cega, perde sua capacidade crítica, tornando-se incapaz de perceber os princípios desviantes. Isso porque, segundo a lei fundamental da estética, descrita por Adorno em Teoria Estética, nossa percepção, além de estímulo, precisa de descanso, tempo para a significação, para ressignificação. Somente, assim, podemos chegar a uma sensibilidade desenvolvida capaz de perceber imperialismos, injustiças e desenvolver a luta pelos direitos dos oprimidos (WELSCH, 1995). O mesmo 
podemos dizer que ocorre com a sexualidade, que passa a ser percebida como puro sexo, estímulo e prazer hedonístico esquecendo-se que sexualidade é relação, inter-relação e não puramente algo do plano do indivíduo.

Por analogia, podemos dizer que em meio à crescente estimulação genital (bulinação) realizada pelo marketing contemporâneo a dimensão sexual reprimida, que clamava por liberdade, passa a constituir-se libertinagem, perdendo seu poder crítico/criativo, para se tornar refém de um sistema mercadológico que encontra na energia sexual seu maior combustível ao transformar a sexualidade em sexo e o sexo em desejo e o desejo em consumismo.

Segundo Touraine (2005, p. 219):

\begin{abstract}
Chegados a este ponto, reencontramos a questão, muito debatida, da presença de programas ditos eróticos ou pornográficos na televisão. Nada, neste campo, é inocente: a televisão tem como objetivo principal produzir objetos de televisão, ou seja, transformar seres reais e diversos em objetos construídos por e para televisão. O que é tanto mais fácil quanto as personagens consideradas estiverem mais vazias de fatos relacionais, afetivos ou intelectuais. É assim que a televisão, tão hábil a descontextualizar e a entender-se com a pornografia, já tem mais dificuldade quando se trata de pôr em evidência a dimensão erótica da sexualidade, e é absolutamente desajeitada na análise das sexualidades mais construídas, tal como as encontramos, por exemplo, nas obras de arte, literária ou picturais.
\end{abstract}

Isso unilateraliza o ser humano em uma única dimensão, perdendo a noção multidimensional, ao mesmo tempo que o expropria de sua humanidade, transformando o humano em apenas homem de desejos. Somos quase que tratados como pênis e vaginas ambulantes, bulinados constantemente a termos um prazer egoísta, superficial, que acaba por ignorar a dimensão intersubjetiva do humano, que individualiza o humano geral (NIETZSCHE, 2005b). As palavras de Hegel presentes na obra Estética são bem elucidativas da posição descrita acima, salvo as críticas ao seu absolutismo. Evidenciam os limites da subjetividade, núcleo central da teoria dos apelos, ao mesmo tempo que possibilitam compreender o ser humano como temporalidade.

Mas a subjetividade implica o que é diferente de si e o poder de se opor e tratar o diferente como algo de negativo. É a negatividade infinita, a negação, e a natureza representa esta última. Tal idealidade e tal negatividade infinita formam o conceito profundo da subjetividade do espírito. Mas enquanto subjetividade, o espírito ainda não é mais do que a verdade da natureza, visto que ainda não formou o conceito de si para si. A natureza não lhe aparece como outro, como o que lhe foi formulado por ele, mas sim como aquilo que é feito diferentemente, como aquilo que é limitado e não ultrapassado e com o qual o espírito, enquanto subjetivo na sua existência de querer e de saber, se relaciona como com uma objetividade que acha completamente feita e de que ele é, por assim dizer, uma resposta. Eis o que explica o caráter finito 
do espírito, quer teórico quer prático, a limitação do conhecimento e a mera obediência ao dever na realização do bem. (HEGEL, 2005, p. 118, grifo do autor).

Nesse sentido, a sexualidade como uma das dimensões da totalidade humana que somente tem sentido enquanto tal no jogo (GADAMER, 2005) com as demais dimensões humanas, como a racionalidade, a espiritualidade, a instintividade, a afetividade, cujas articulações o fazem singular e temporalidade. Isso, à medida que a articulação com as demais dimensões humanas e as demais dimensões com a dimensão da sexualidade podem garantir a condição de temporalidade ao homem, o ser em devir, como um acontecer contemporâneo e não puramente massificado (AGAMBEN, 2009). Isso porque essa condição de temporalidade, ou o humanar do humano, somente seria possível no, por meio do jogo intersubjetivo. Processo no qual, ou pelo qual as identidades são colocadas em questão, colocam em questão outros modos de ser, ressignificam-se sem se massificar. Contudo, o pós-moderno com a crítica destrutiva dos metarelatos possibilitou o emergir do humano enquanto temporalidade, uma vez que possibilita o emergir das singularidades para além dos processos de individuação, questionou a atemporalidade das verdades e dos fundamentos dos saberes, possibilitando a pergunta, novamente, pelo que é o humano, qual sua condição, embora o que nos mostra Lyotard (2006), quando fala da emergência da pós-modernidade. Parece caber muito bem os convites de Foucault quanto ao cuidado e reescritura de si, respostas que a sexualidade tratada enquanto sexo e este enquanto desejo não consegue possibilitar.

Assim, se ficarmos no âmbito do discurso pós-moderno, apenas de ruptura do uno puro, como puro esfacelamento do sujeito, sem o reconhecimento do presente e da tradição, sem o diálogo entre presente e tradição, especialmente propagada pela ilusão midiática e suas posturas reacionárias, continuar-se-á no âmbito dos modismos apenas. E, à maneira do Édipo da tragédia grega de Sófocles, Rei Édipo, continuaremos matando nossos pais, a tradição visível à nossa frente, mas “casando com nossa mãe” a tradição mais íntima, e nos furando o olho, como fez Édipo, ou tendo um fim semelhante ao de Jocasta, ao mesmo tempo que deixaremos a humanidade órfã, visto nossa incapacidade de reconhecimento se tornar inviabilizada pela unilateralização do desejo que passa a nos cegar. Aqui se revela o limite do discurso pós-moderno, à luz da Hermenêutica Filosófica. Assim, o que parece faltar parece ser a atitude do contemporâneo, àquele que estando no tempo, mas, muitas vezes, estranho ao tempo que está, problematiza não somente o tempo, mas a si mesmo (AGAMBEN, 2009) salvaguardando a condição humana de projeto (HEIDEGGER, 1995), como temporalidade (GADAMER, 2005). 


\section{CONSIDERAÇÕES FINAIS}

A pergunta sobre a sexualidade nasce com base na hipótese de que uma sociedade, tradição que não confere tratamento às questões que envolvem a sexualidade e seus desdobramentos não conseguem se firmar subjetivamente. Isso porque a sexualidade é relação, e, por isso, demarcação, redemarcação identitária, constitutiva das subjetividades, ao mesmo tempo que abertura. Podemos perceber isso se considerarmos os períodos históricos do mundo ocidental e, não somente. A tradição greco-romana, cristã, como a moderna e pósmodernas tem suas especificidades. Nesse sentido, com a ruptura dos metarrelatos, no mundo contemporâneo, pelo viés do discurso pós-moderno, evidencia-se a sexualidade desvinculada de questões sociais para emergir como questão individual à medida que passa a ser compreendida como sexo e este como desejo. A sexualidade passa a ser confundida, como sexo, como desejo, pois centrada no indivíduo consumidor de sensações. Perde da dimensão do si na relação para emergir como condição sexo e este como desejo, como gozo, perdida no subjetivismo. Nesse sentido, salientamos que nossas análises conceituais evidenciam que o discurso pós-moderno, embora tenha colocado o ser em movimento como possibilidade que o ser não comporta o equilíbrio dinâmico do ser em suas multidimensionalidades, especialmente em termos discursivos, protagonizando a unilateralidade estetizante e anestesiante da sexualidade erotizada. Isso parece cumprir o discurso da pós-modernidade, uma vez que vem servindo de justificativa ao discurso formativo da sexualidade na contemporaneidade, não como sexualidade em si, relação, mas como desejo egoístico, visto esse ter liberado o ser humano dos referenciais tradicionais, tidos, até então, como estruturadores da personalidade e também repressores do humano, para ser empossada pelo consumismo de sensações.

O que fica é que uma sociedade somente se estrutura e se mantém se conseguir contemplar o horizonte da sexualidade em seus discursos e atos. Contudo, vivemos num contexto marcado pela crise dos universais, dos referenciais de certeza e pela emergência e circulação das diversidades, dos estranhamentos, ameaçando e abalando nossas seguranças ontológicas, afetando-nos e afetando-nos cognitiva, moral e esteticamente. Um período tenso, em que fronteiras se abrem e se fecham, em que subjetividades históricas são postas em questão, são convocadas a se ressignificar, processo em que a sexualidade tem lugar enquanto 
relação, inter-relação não somente subjetiva, mas também cultural, marcada por desejos e não desejos. Um período em que uma das melhores orientações seria a de proposições dialógicas, como possibilidade de ultrapassar os discursos consagrados do bem e do mal e como forma de proporcionar uma sexualidade mais ética, que não fique presa à leviandade da lógica mercadológica, funcionado como dispositivos de controle.

\title{
SEXUALITY IN POST-MODERN SPEECH HORIZON
}

\begin{abstract}
At the time of the reference crisis in which the relations are the scope of stability (until death do them part, to eternal while dures) to be fruídas, volatile without much stability that any behavior seems correct, important to understand the constitutive process sexuality, on the horizon of postmodern discourse. Therefore, we used bibliographic and data collection through structured individual interviews based on socialization and subject of debate at the time of interview research. Through research it can be concluded that modern crisis gives rise to several "deconstructions" and back as a continuation of this process postmodernity, with its crises and breaking taboos, showing us how the postmodern relations are empty, insecure and fragmented, but represents a historical moment approach that can not be ignored, in that it puts in sena human in its contingency becoming. However, is the possibility of dialogue as power to bring out the diversity, which is just in itself, for itself and for itself is reckless and selfish.
\end{abstract}

Keywords: Formation; Sexuality; Speech; Post Modern

\section{LA SEXUALIDAD EN EL HORIZONTE DEL DISCURSO POSMODERNO}

\section{Resume}

En el momento de crisis de los referenciales en que las relaciones pasan del ámbito de la estabilidad (hasta que la muerte los separe, para eternas mientras duren) para que sean gozadas, volátiles, sin mucha estabilidad, que cualquier comportamiento parece correcto, importa comprehender el proceso constitutivo de la sexualidad, en el horizonte del discurso posmoderno. Para eso, se utilizó de investigación bibliográfica y coleta de los datos por medio de entrevistas individuales estructuradas con base en socialización y debate del tema en el momento de la entrevista. Con la investigación se puede concluir que la crisis moderna da 
LAGO, C.; TAROUCO, S. J. V. B.; JUNIOR, E. E. S.

origen a varias "desconstrucciones" e trae como continuidad de ese proceso la posmodernidad, con sus crisis y quiebra de tabúes, mostrándonos o cuanto las relaciones posmodernas están vacías, inseguras, y fragmentadas, pero representa un momento, un enfoque histórico que no puede ser ignorado, una vez que pone en escena el humano en su devenir indeterminado. Sin embargo, constituye posibilidad de dialogo como poder hacer emerger la diversidad, que se, solo en sí, por sí y para sí es temeraria y egoistica.

Palabras clave: Formación; Sexualidad; Discurso; Posmoderno

\section{REFERÊNCIAS}

AGAMBEN, Gregório. O que é o contemporâneo? e outros ensaios. Tradução Vinícios Nicastro Honesko. Chapecó: Argos, 2009.

ALMEIDA, T.; LOURENÇO, M. L. Amor e sexualidade na velhice: direito nem sempre respeitado. RBCEH, Passo Fundo, v. 5, n. 1, p. 130-140, jan./jun. 2008.

ARÁN, Márcia. O destino da diferença social da cultura contemporânea. Florianópolis, 2003.

BAUMAN, Zygmunt. Amor líquido: sobre a fragilidade dos laços humanos. Rio de Janeiro: Jorge Zahar, 2004.

Zahar, 2008.

A sociedade individualizada: vidas contadas e histórias vividas. Rio de Janeiro: Jorge Modernidade líquida. Rio de janeiro: Jorge Zahar, 2001.

. O mal-estar da pós-modernidade. Tradução de Mauro Gama; revisão técnica de Luís Carlos Fridman. Rio de Janeiro: Jorge Zahar Editor, 1998.

BUSSE, S. R. (Org.). Anorexia, bulimia e obesidade. Barueri: Manole, 2007.

CANDIOTTO, Cesar. A emergência do homem de desejo. Véritas, Porto Alegre, v. 60, n. 2, p. 244-365, maio-ago. 2015.

DUARTE JÚNIOR, João-Francisco. Itinerário de uma crise: a modernidade. Curitiba: Ed. UFPR, 2002.

FENSTERSEIFER, L.; WERLANG, B. S. G. Comportamentos auto-destrutivos, subprodutos da pós-modernidade? Curitiba, 2006. 
FOUCAULT, Michel. História da sexualidade I: a vontade de saber. Rio de Janeiro: Graal, 1988.

GADAMER, Hans-Georg. Verdade e método I: traços fundamentais de uma hermenêutica filosófica. 7. ed. Petrópolis: Vozes; São Paulo: Ed. Universitária São Francisco, 2005.

GIDDENS, Anthony. As conseqüências da modernidade. São Paulo: Ed. Unesp, 1991.

GOERGEN, Pedro. O embate da modernidade/pós-modernidade e seu impacto sobre a teoria e a prática educacional. EccoS - Revista Científica, São Paulo, n. 28, p. 149-169, maio/ago. 2012.

GROSSI, Miriam Pillar. Identidade de gênero e sexualidade. Florianópolis, p. 1-18, 1998 (versão revisada - 2010).

HABERMAS, Jurgen. O discurso filosófico da modernidade. São Paulo: Martins Fontes, 2002.

HALL, Stuart. A identidade cultural na pós-modernidade. 4. ed. Rio de Janeiro: DP\&A, 2000.

HEGEL. Estética. São Paulo: Nova Cultural, 2005. (Os Pensadores).

HEIDEGGER, Martin. Ser e tempo. Tradução Márcia de Sá Cavalcante. Petrópolis: Vozes, 1995.

LYOTARD, Jean- François. A condição pós-moderna. Tradução Ricardo Corrêa Barbosa; pósfacio de Silviano Santiago. 9. ed. Rio de Janeiro: José Olympio Editora, 2006.

NIETZSCHE, Friedrich. A gaia ciência. São Paulo: Companhia das Letras, 2005a.

. A visão dionisíaca de mundo. São Paulo: Martins Fontes, 2005b.

. Sujeito e perspectivismo. Seleção de textos de Nietzsche - Notas introdutórias de Antonio Marques. Portugal: Publicações Dom Quixote L. Da, 1989.

RIESMAN, David. Teoria da cultura de massa. São Paulo: Paz e Terra, 2000.

TOURAINE, Alain. A procura de si: dialogo sobre o sujeito. Lisboa: Instituto Piaget, 2001. . Crítica da modernidade. Rio de Janeiro: Vozes, 2002.

. Iguais e diferentes: poderemos viver juntos? Lisboa: Instituto Piaget, 1997. 2005.

- Um novo paradigma: para compreender o mundo hoje. Lisboa: Instituto Piaget, 
LAGO, C.; TAROUCO, S. J. V. B.; JUNIOR, E. E. S.

WELSCH, Wolfgang. Esteticização e esteticização profunda ou: ou a respeito da atualidade do estético nos dias de hoje. Tradução Alvaro Reis. Porto Alegre, Porto Alegre, v. 6, n. 9, p. 7-22, maio 1995.

Data de recebimento: 24/01/2014

Data de aceite: 29/02/2016 